\title{
Air Engine as a Manufacturing Project in an Introductory Design Course
}

\author{
Gregg W. Dixon, Vincent Wilczynski, Eric J. Ford \\ United States Coast Guard Academy
}

\begin{abstract}
Several schools have recognized the value of build-to-spec construction projects to familiarize students with manufacturing methods and computer-aided-design applications. At the U.S. Coast Guard Academy, we have introduced a project in which students in a sophomore level design course produce $\mathrm{CAD}$ drawings and then build a small air engine shown in Figure 1 below. The project requires students to use a variety of manufacturing tools including a lathe, milling machine, drill press, grinder, and various hand and woodworking tools. Students with no prior manufacturing experience can develop reasonable proficiency and familiarity with manufacturing processes. The students having prior experience with these processes find the project outcomes attractive enough to hold their interest. Before building the engine, students produce CAD drawings of all of the individual parts and assemble them into an animated solid model. Thus, this project provides a vehicle for students to learn how to use CAD software.
\end{abstract}

The materials for the project may be acquired for less than $\$ 10.00$ per engine, making this a very economical, yet practical exercise. Some of the parts require tight tolerance limits in order for the engine to operate properly, giving the students an appreciation for quality control in manufacturing processes. The completed engine is visually attractive and has interesting operating characteristics that demonstrate the operation of properly timed valves and crank-driven flywheels. The freewheeling speed of the engine provides a measure of construction quality.

This paper provides an explanation of the construction and testing of the air engine, a description of how the project is integrated with laboratory and lecture activities in a sophomore level design course, and an explanation of how this activity fits into the achievement of desired educational objectives of the course and of the Mechanical Engineering degree program.

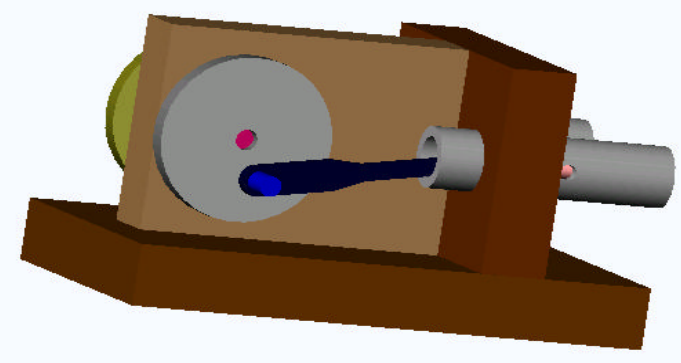

Figure 1: 3-D CAD Drawing of CGA Air Engine 


\section{Introduction}

The Mechanical Engineering Program at the U.S. Coast Guard Academy (USCGA) has introduced a new sophomore level course: Introduction to Mechanical Engineering Design (IMED). This course, which is required of all Mechanical Engineering majors replaces a more general freshman level, "Introduction to Engineering Design" course which was previously required for all majors, both technical and non-technical. The primary course objective is to provide a foundation in some elements of the design process on which the students will build in their further studies and their engineering career. The course includes both lecture and laboratory activities culminating in a creative team design effort. In the first offering of the course, this activity also involved teams in building small radio controlled robots to execute a variety of simulated Coast Guard missions. The air engine project described in this paper helped the students prepare for the more open-ended robot project.

Many schools have recognized that a significant challenge we are facing in engineering education is that many college students who choose to major in engineering have little or no prior experience in hands-on construction projects. This lack of experience can limit the value of group design projects in which the manufacturing activities may be delegated to those students with some prior experience, thus limiting the learning opportunity for students with less experience or skill. Several schools have responded to this challenge by introducing manufacturing projects in lower level classes, which require all students to develop a familiarity with basic shop equipment and manufacturing methods. Notably, the Mechanical Engineering programs at the Massachusetts Institute of Technology and Tufts University have introduced projects that require all students to execute a "build to specification" project in which students construct a small engine. The MIT project involves the construction of a Stirling engine, while the Tufts project involves the construction of a small engine (or motor), which uses compressed air.

Recognizing that any project must be consistent with the equipment, budget and scheduling constraints of the institution, the USCGA has designed a low-cost air engine construction project, which gives students experience in using most of the manufacturing methods they will have available for the design projects they will execute during their undergraduate education. This engine also provides a vehicle for instruction in sketching and computer aided design methods. In fact, before initiating construction, the students were required to draw the engine using threedimensional (3-D) Computer Aided Design (CAD) software.

\section{Hand and CAD Drawings}

Prior to letting the computer savvy students of today create 3-D objects using a CAD software package, students were given a brief introduction to sketching by hand. They were taught the general layout of an engineering drawing, which usually includes the top, front and right side view sketches of a three-dimensional object on paper (orthographic projection). Then the students were introduced to isometric drawings and tasked with converting an orthographic projection to an isometric view and vice versa.

The students at first appeared to believe the work to be tedious with of minimal to no 
consequence and in some cases very difficult to perform. However, they soon gained an extraordinary amount of appreciation for a technician to actually fabricate the part from an engineering drawing. It takes a great deal of time to be able to read a drawing and understand its shape in three dimensions. It was realized that if it were possible to actually represent the object in three dimensions from the beginning, it would be easier to visualize, construct, and understand the importance of configuration and how everything must fit together just right to work properly.

Once familiar with hand sketching, students advanced to 3-D modeling using SolidWorks $®$ as the modeling software. Upon review of 3-D modeling research by others (1-4), 3-D modeling was selected as the principal method to gain experience in the areas of visualization, solid modeling, dimensioning, multi-views and assemblies. While a number of software products are available as the platform, SolidWorks ${ }^{\circledR}$ was selected primarily based on its ease of use and ability to achieve the goals of this project as evidenced by its incorporation at other universities.

The solid modeling instruction focused on the progression of the following skills:

- Creating 2-D shapes from sketches

- Developing 3-D models of components

- Dimensioning the components

- Combining components as assemblies

- Creating engineering drawings of components and the completed assembly

- Creating the Bill of Materials

In addition, advanced students could pursue rendering and animation of the final computer model. In pursuit of these objectives, students would gain experience in three-dimensional visualization, interpreting an engineering drawing, and the process of advancing a preliminary sketch into an engineering drawing. The overall goal of the modeling component of the course was to introduce the techniques of solid modeling such that they could model and assemble components, as needed in future courses.

A faculty member with no prior experience with solid modeling conducted the course instruction for this component of the project. Approximately 40 hours were required for that faculty member to use the product literature to become familiar with the software, and another 40 hours devoted to preparing the course material to support the instruction. A local SolidWorks representative provided product support, and this support was a key component of the project's success. While one can "teach yourself" using tutorials and manuals, by doing so you may only teach yourself how to solve problems that you have created. With a group of students, new questions arise, thereby requiring additional support for those questions that were never solved before.

Three lab periods (2.8 hours each) and five class periods (50 minutes each) were devoted to the instruction. Table A establishes the sequence of instruction. Other than the initial class, which introduced solid modeling and the SolidWorks ${ }^{\circledR}$ software, all other periods were working sessions spent in the computer lab. The instruction sequence guided the students in the process of achieving the objectives identified above. 


\begin{tabular}{|c|c|c|c|}
\hline Period & Topic & $\begin{array}{c}\text { Parts / Assembly } \\
\text { Focus }\end{array}$ & Deliverable \\
\hline Class One & $\begin{array}{l}\text { Introduction to CAD } \\
\text { using SolidWorks } ®\end{array}$ & & \\
\hline Lab One & $\begin{array}{l}\text { "How to Create 3-D } \\
\text { Models" including } \\
\text { dimensioning, extrudes, } \\
\text { cuts }\end{array}$ & $\begin{array}{l}\text { Valve wheel, } \\
\text { flywheel, valve } \\
\text { piston }\end{array}$ & $\begin{array}{l}\text { 3-D drawings of valve } \\
\text { wheel, flywheel, valve } \\
\text { piston, valve cylinder, } \\
\text { power piston, power } \\
\text { cylinder, base, flywheel } \\
\text { and cylinder supports }\end{array}$ \\
\hline Class Two & $\begin{array}{l}\text { "How to Create 3-D } \\
\text { Models" including } \\
\text { dimensioning, extrudes, } \\
\text { cuts }\end{array}$ & $\begin{array}{l}\text { Connecting rod- } \\
\text { power, connecting } \\
\text { rod-valve, } \\
\text { intake/exhaust tube }\end{array}$ & $\begin{array}{l}\text { 3-D drawings of } \\
\text { connecting rod-power, } \\
\text { connecting rod-valve, } \\
\text { intake/exhaust tube }\end{array}$ \\
\hline Class Three & $\begin{array}{l}\text { Introduction to } \\
\text { Assemblies and } \\
\text { Drawings }\end{array}$ & $\begin{array}{l}\text { Assembling the } \\
\text { base \& base } \\
\text { drawing }\end{array}$ & \\
\hline Lab Two & $\begin{array}{l}\text { Working with } \\
\text { Assemblies }\end{array}$ & $\begin{array}{l}\text { Assembling power } \\
\text { system, valve } \\
\text { system, base }\end{array}$ & $\begin{array}{l}3 \text { Assemblies of the } \\
\text { referenced systems }\end{array}$ \\
\hline Class Four & $\begin{array}{l}\text { More on Assemblies } \\
\text { and Drawings }\end{array}$ & Fasteners and fits & $\begin{array}{l}\text { Engineering drawings of } \\
\text { all } 12 \text { parts }\end{array}$ \\
\hline Class Five & $\begin{array}{l}\text { Bill of materials, } \\
\text { material properties, } \\
\text { hole wizard, }\end{array}$ & Bill of materials & \\
\hline Lab Three & Final Assembly & Complete assembly & $\begin{array}{l}\text { Complete assembly of the } \\
\text { air engine drawings and } \\
\text { bill of materials. }\end{array}$ \\
\hline
\end{tabular}

\section{Table A: Schedule \& Deliverables}

Instructional tutorials were developed to walk the students through every click of the mouse needed to transform a given sketch to a 3-D model. Instruction began with the tutorial entitled "How to Create 3-D Models." Very specific instructions were provided for the first component, the flywheel, to illustrate drawing shapes, extrusions, cuts and dimensions. In addition to providing a step-by-step process for creating this simple shape, the students were able to learn how to set up a drawing template, label the model and insert dimensions. This lab also introduced the topics of fillets and inserting reference planes to make a hole in a curved surface, such as was required for the valve piston model.

Once the required modeling topics were introduced in the tutorial, the twenty-eight students, working in teams of two but each with their own workstation, produced solid models of each of the eighteen components of the air engine. Some of the results of this step - solid models of the components - are shown in Figure 2. 

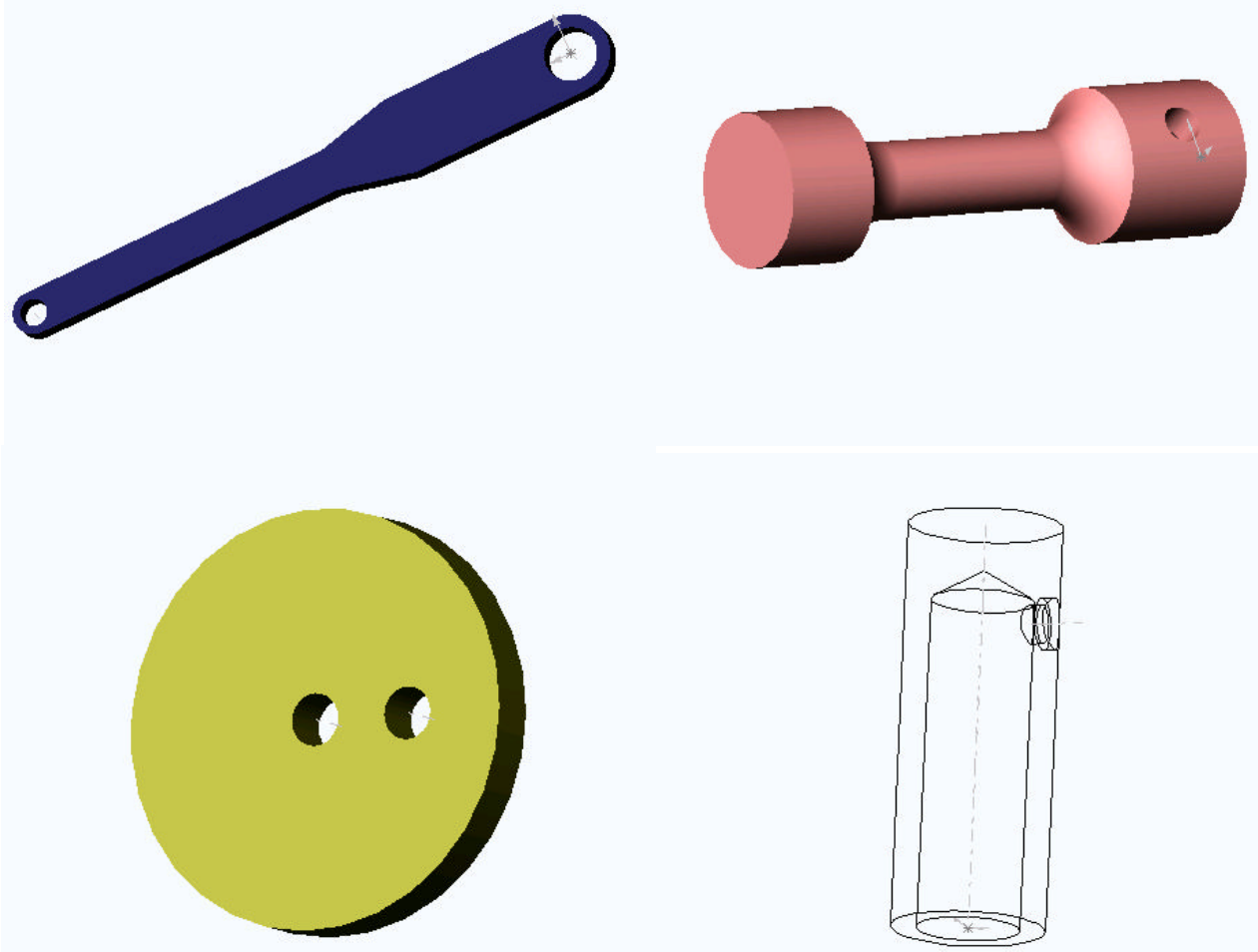

Figure 2: Solid Model Components

The topic of combining components into an assembly was the subject of the second laboratory period. Here too, a step-by-step tutorial was used to guide each student on the subtleties associated with combining parts as an assembly. SolidWorks ${ }^{\circledR}$ provides tool features that make alignment and assembly very easy, and students were quick to adjust to using these new tools. With the ability to specify fixed and floating points, as well as an easy method for aligning concentric and parallel surfaces, the students were quick to transform the individual parts into sub-assemblies.

Figure 3 details the sub-assembly for the valve side of the engine while Figure 4 presents the subassembly for the base. The sub-assemblies for the valve side, drive side and base were then assembled into a composite unit. Any needed modeling corrections, needed to get parts to assemble, were made at this time. Because the software allows specified parts to be constrained due to their association with other parts, the students could move components and see the resulting motion on the completed device. 


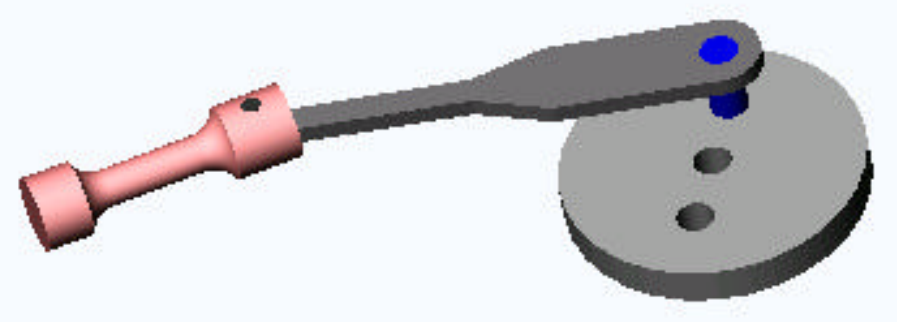

Figure 3: Valve-Flywheel and Valve-Piston Sub-assembly

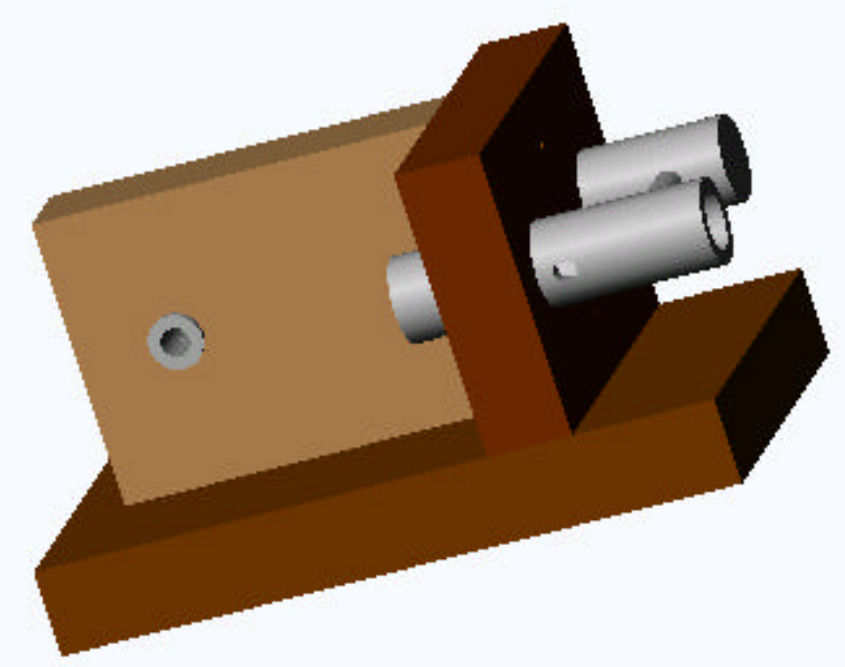

Figure 4: Base and Cylinder Sub-assembly

The final lab period was devoted to creating engineering drawings. By virtue of their working assembly, the students were assured that their individual parts were correct and engineering drawings could be created. Within SolidWorks ${ }^{\circledR}$ this is accomplished by merely dragging the 3-D 
model icon into a "Drawing Window." The three orthographic projections are automatically created for the part and the user can then add any needed dimensions to the drawing. An isometric view of each part could also be created on the drawing. A drawing of the complete assembly is shown in Figure 5.

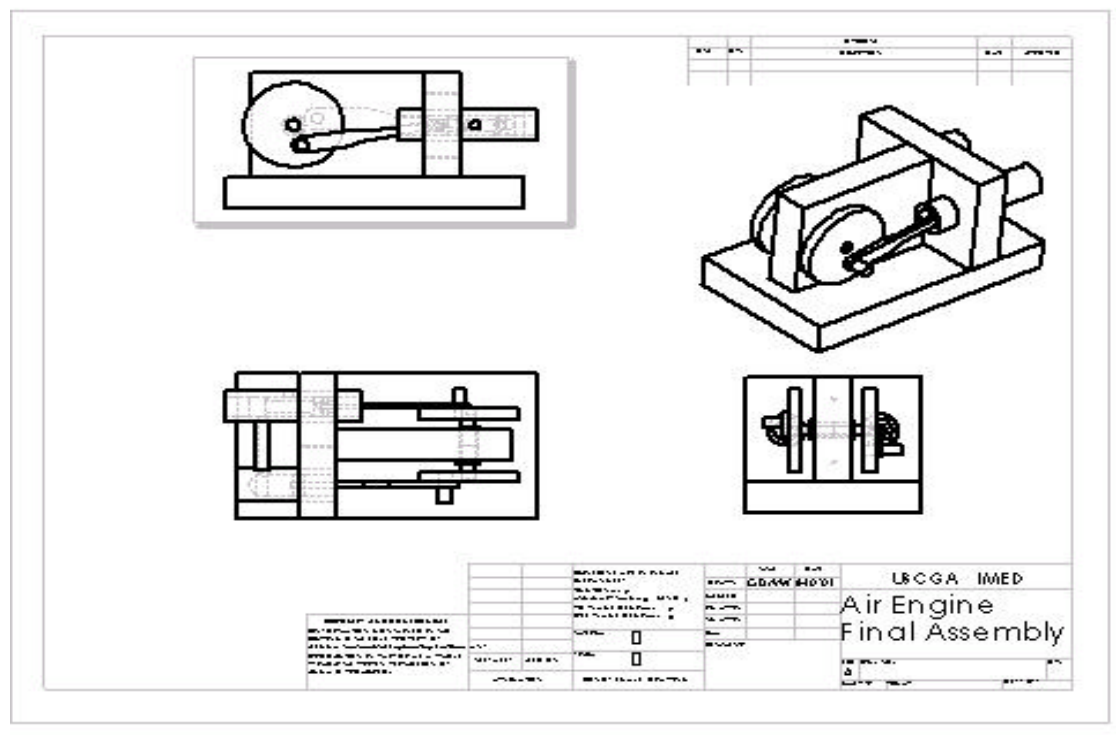

Figure 5: Air Engine Final Assembly

A Bill of Materials was created for the project with a similar amount of ease and automation as shown in Figure 6.

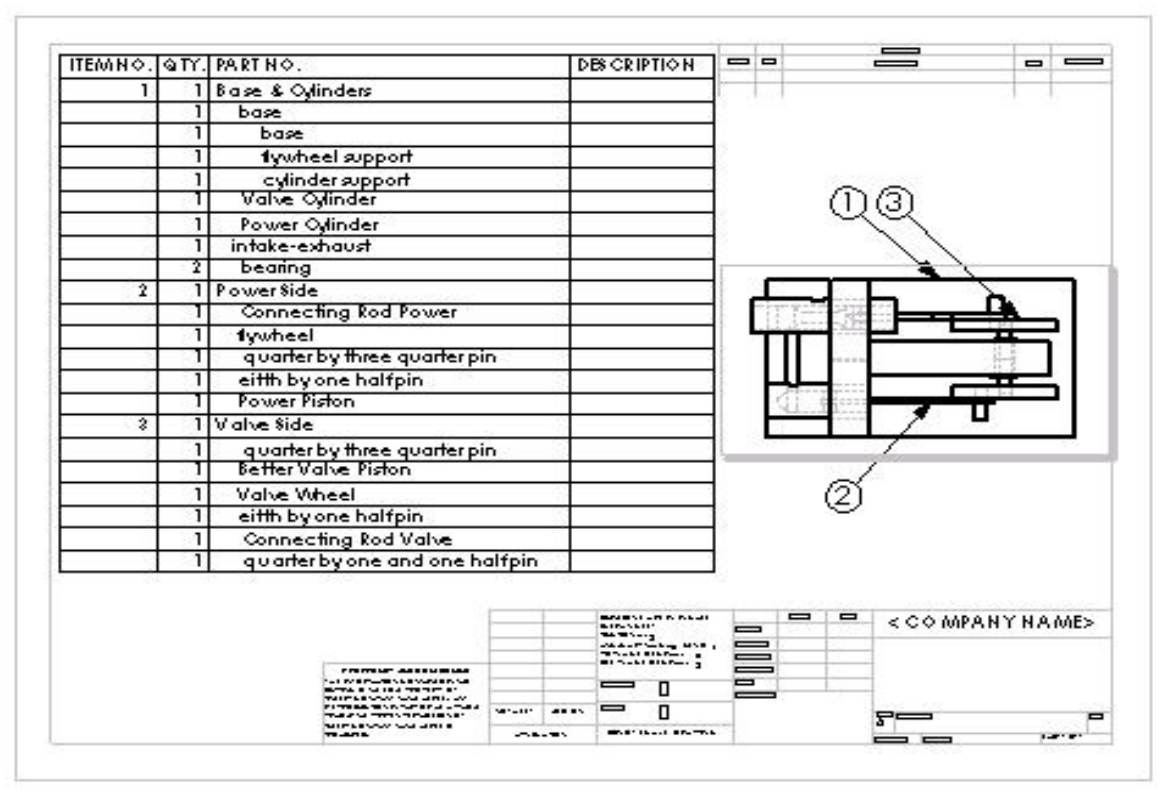

Figure 6: Bill of Materials 
The instructors were immensely satisfied with the pace of progress and overall success of the students with this software. While substantial overhead was required for the faculty to learn the software and develop the needed teaching tools, very little time will be required in the future. In addition to achieving the project objectives, some advanced students even used additional features in the software to produce photographic renderings and even animation of their work. All teams were successful in the project.

\section{Materials and Construction}

The primary pieces of the air engine which are fabricated by students include:

1. Power Cylinder

2. Valve Cylinder

3. Power Piston

4. Valve Piston

5. Valve and Power Connecting Rods

6. Intake and Exhaust Tube

7. Flywheel and Valve Wheel

8. Engine Support

Before starting construction, all students were given a lesson in the operation and safety of each major piece of equipment in the laboratory. The lesson consisted of a lecture with demonstration followed by the students testing of the device to determine its capabilities using scrap pieces of wood, metal and fiberglass. This introduction prevent ed many manufacturing failures from occurring, however, some are inevitable when considering the level of the students in the use of the equipment. The greatest difficulty for the students consisted of fabricating the connecting rods due to the small amount of material surrounding the pinholes. However, all students were able to complete the project successfully while operating the shop equipment safely.

The valve and power cylinders are made out of $3 / 4$ inch diameter aluminum rod. They are both bored and reamed (to $1 / 2$ inch) on a lathe, and then a hole is drilled in each cylinder to accommodate the connecting intake and exhaust tube. The valve cylinder also requires a hole drilled and threads tapped for the threaded air intake fitting which is supplied to the students.

The power and valve pistons are cut from $1 / 2$ inch diameter Delrin rod. A hole is drilled in the end with a lathe and then a drill press is used to drill a small hole across the diameter to accommodate the pin, which serves as a pivot for the connecting rod. The valve piston is also turned on a lathe to reduce the diameter of the center segment of the valve as shown in Figure 2. The tolerances on the Delrin rod diameter were generally found to be reasonable, but occasionally, some students would need to smooth the pistons with a fine emery cloth to obtain a good fit with the reamed cylinders.

The power and valve connecting rods are cut from $1 / 8$ inch $\times 1 / 2$ inch aluminum bar stock. Holes are drilled with a drill press and then one end is narrowed as shown to allow clearance with the inner walls of the cylinders. These pieces were cut with a band saw and then smoothed using a 
grinder, files and emery cloth. In the future, students will cut these pieces with a CNC milling machine, thus minimizing the hand finishing requirements.

The engine base and supports are made out of oak which is cut with a radial arm saw, smoothed with a power sander and drilled with a drill press to fit the $3 / 4$ inch aluminum cylinders, the axle bearings and wood screws required to join the pieces. Students were encouraged to demonstrate their creativity in finishing the base using a router or by adding distinguishing features. Some students painted or finished the wood pieces.

The flywheel and valve wheel are made from brass and aluminum discs provided to the students. The wheels had to be drilled in the center with a lathe and then also $1 / 2$ inch from the center using a drill press. These holes are then reamed to 0.249 inch to accommodate press fitting $1 / 4$ inch diameter steel pins which serve as the axle for the wheels and the connecting rods. Some students found it useful to add spring clips to the connecting rod shaft to constrain the motion of the rod on the shaft; however, most of the engines worked well without these constraints. Commercially manufactured sintered brass bearings were supplied to the students and then press fit into the oak support.

\section{Implementation and Testing}

After completion of all CAD drawings and construction, the students were able to see the fruits of their labor. The engines were tested using air from a compressor reduced to approximately 10 pounds per square inch. This was kept as the standard for all teams in order to ensure comparable test conditions. Multiple tests were required to get many of the engines working smoothly as the students were forced to realize the necessity of precision in manufacturing and assembling parts. Some of the engines experienced interferences due to the connecting rods contacting the cylinder wall, and students had to hand finish some of the components to eliminate the problems resulting from lack of precision in their initial fabrication efforts.

As a tool for measuring each team's success, a tachometer was used to determine the speed in revolutions per minute (rpm) of each engine. All of the teams then decided they wanted to spend more time smoothing the surfaces, aligning the connecting rods, making sure the clearances and fits were just right, lubricating the parts and stopping all sources of air leaks. Without even realizing what they were doing, the students were learning the importance of tribology, limits, fits, testing, operation and implementation of the design. All of these aspects help to prepare the students for future design-build projects they will experience in the Mechanisms, Machine Design and Mechanical Engineering Design courses during their junior and senior years. The fourteen engines had speeds ranging from 500 to $1800 \mathrm{rpm}$ with an average speed of approximately 1180 rpm and a standard deviation of $180 \mathrm{rpm}$.

Once the students completed the testing phase of the project, they were tasked in the lecture portion of the class with developing ideas for design modifications. Students were required to develop a series of alternatives consistent with the levels or categories described by Hyman (5) as follows: 
1. Selection Design - Designs involving the selection of "off the shelf" components to achieve the objectives.

2. Configuration Design - Designs that arrange the components differently to achieve performance or reduce its size.

3. Parametric Design - Designs with varied parameters to achieve the objectives. Parameters may include speed, power, or efficiency.

4. Original Design - Designs that are a substantial and fundamental departure from existing products or processes.

This assignment helped prepare the students for the culminating creative design project in the course in which they were tasked with developing creative ideas for designing and building radio controlled robots.

\section{Conclusion}

The air engine design described in this paper has provided a useful vehicle for introducing students to sketching and CAD drawing, manufacturing methods, and useful concepts for mechanical systems. With limited classroom instruction, all students were able to complete detailed drawings of all engine parts and a complete assembly using SolidWorks ${ }^{\circledR}$. Students with a wide range of prior experience in shop practices were all able to complete an operating engine and gain the satisfaction of seeing their efforts pay off in the operation of a working device. Students gained experience in operating shop equipment which will improve their ability to take manufacturing methods into consideration in their future design efforts.

\section{References:}

1. Branoff, T.J., N.W. Hartman \& E.N. Wiebe (2001), Constraint Based, Three-Dimensional Modelling in an Introductory Engineering Graphics Course: Re-examining the Curriculum, Proceedings of the 2001 ASEE Annual Conference.

2. Myszka, D.H (2001), Integrating Solid Modeling Throughout a Mechanical Engineering Technology Curriculum, Proceedings of the 2001 ASEE Annual Conference.

3. Schweitzer, S.J., J.S. Klegka (2001), Mid-Level CAD Packages as Stepping Stones for Solid Modeling Education, Proceedings of the 2001 ASEE Annual Conference

4. Musto, J.C., W.E. Howard (2001), The Use of Solid Modeling in Mechanical Engineering Outreach Programs for High School Students, Proceedings of the 2001 ASEE Annual Conference

5. Hyman, Barry I., Fundamentals of Engineering Design (C 1998 by Prentice-Hall, Inc., NJ 


\section{GREGG W. DIXON}

Gregg Dixon is a Professor of Mechanical Engineering and Head of the Mechanical Engineering Program at the U.S. Coast Guard Academy. He received an M.S. degree in Engineering Science in 1966 from Stanford University in a combined B.S./M.S program. He received a Ph.D. in M.E. from Stanford in 1970. He previously taught at California State University, Northridge and served as a consultant to the International Atomic Energy Agency.

\section{VINCENT WILCZYNSKI}

CDR Vincent Wilczynski, Ph.D., is an Associate Professor of Mechanical Engineering at the U.S. Coast Guard Academy. He has been the chair of the ASEE Design in Engineering Education Division and is a national officer of ASME. CDR Wilczynski was awarded the 2001 Outstanding Baccalaureate Colleges Professor of the Year by the Carnegie Foundation for the Advancement of Teaching and the Council for Advancement and Support of Education.

\section{ERIC J. FORD}

Eric Ford is an Assistant Professor of Mechanical Engineering at the U.S. Coast Guard Academy. He received a B.S. degree in Naval Architecture and Marine Engineering from the U.S. Coast Guard Academy in 1991 and M.S. degrees in Naval Architecture and Marine Engineering and Mechanical Engineering from the Massachusetts Institute of Technology in 1995. 